Results A total of 86 silica samples, 72 samples for RSP and 89 samples for TSPM were collected for the similar exposure groups (SEG) in the brick kilns. Among the SEGs, red brick loaders had the highest mean and maximum exposures to silica, RSP and TSP. To summarise, mean results were as follows for the red brick loaders, respectively for silica, RSPM and TSPM: $0.388 \mathrm{mg} / \mathrm{m}^{3}, 17.944 \mathrm{mg} / \mathrm{m}^{3}, 22.657 \mathrm{mg} / \mathrm{m}^{3}$. Other SEGs also had exposures above recognised exposure limits to silica, RSP and TSP. Additionally, several SEGs had workers under the age of 18. Exposures were significantly high and results will be discussed.

Conclusions These findings indicate urgent action is required for protection of workers, including working children, from exposures and subsequent diseases associated with particulate matter and silica. Many other hazards exist in the brickfields including heat stress, acute injury and ergonomic hazards that should be addressed.

\section{C SILICA EXPOSURE AND CHILD LABOUR IN NEPAL BRICK KILNS}

SM Thygerson. Environmental and Occupational Health, Department of Health Science, Brigham Young University, UT, USA

\subsection{6/oemed-2018-ICOHabstracts. 1771}

Objective This study was conducted to estimate the prevalence of respiratory symptoms/illnesses and the magnitude of silica exposures among children working in Nepalese brick kilns.

Methods Personal samples for silica were collected following $\mathrm{NIOSH}$ methods. Bivariate and multivariate logistic regression analysis was carried out to evaluate association between respiratory symptoms/illnesses and participant groups (exposed and referent) and Similar Exposure Groups (SEG) among brickfield workers. Logistic regression analysis adjusting age, duration of work and smoking practices was carried out at 0.05 level of significance. Additionally, a cross-sectional study was conducted in Kathmandu valley targeting all the brickfield workers during February - March 2015. Out of 106 operating brick kilns in Kathmandu Valley, 16 kilns were selected for the study applying multi-stage probability proportionate to size (PPS) sampling technique. A total of 800 participants, 400 brick workers as exposed and 400 grocery workers as referent group were recruited for interviews.

Results A total of 86 silica samples, 10 were linked to children under the age of 18 . These children worked in several of the SEGs. Among the SEGs, red brick loaders had the highest mean and maximum exposures to silica. Chronic cough (14.3\%), phlegm (16.6\%) and bronchitis (19.0\%) were higher $(\mathrm{p}<0.05)$ among brickfield compared with grocery workers $(6.8,5.8$ and $10.8 \%)$. Mean respirable $\left(5.888 \mathrm{mg} / \mathrm{m}^{3}\right.$ ) and total $\left(20.657 \mathrm{mg} / \mathrm{m}^{3}\right)$ dust exposures were highest for red brick loading tasks. Additionally, several SEGs had workers under the age of 18 . Exposure were significantly high and results will be discussed.

Conclusions High dust exposures identified in this study may explain the increased prevalence of respiratory symptoms/illnesses among Nepalese children working in the brickfields, warranting action to reduce exposures.

\section{4d BRICK KILNS OF NEPAL: RECOGNISING THE HAZARDS}

Seshananda Sanjel. Kathmandu University, Dhulikhel, Kavre, Nepal

\subsection{6/oemed-2018-ICOHabstracts. 1772}

Objective To evaluate the airborne exposure concentrations of total suspended particulate matters (TSPM), repirable suspended particulate matters (RSPM) and silica in brickfields and the prevalence of respiratory symptoms and illnesses among brickfield workers.

Methods A cross-sectional study was conducted in Kathmandu valley targeting all the brickfield workers during February March 2015. Out of 106 operating brick kilns in Kathmandu Valley, 16 kilns were selected for the study applying multistage probability proportionate to size (PPS) sampling technique. A total of 800 participants, 400 brick workers as exposed and 400 grocery workers as referent group were recruited for interviews. Samples for silica, respirable and total particulate were collected following NIOSH methods. Oneway ANOVA along with Tukey's test were applied to compare significance of the extent of particulate matters among similar exposure groups (SEGs). Bivariate and multivariate logistic regression analysis were carried out to evaluate association between respiratory symptoms/illnesses and participant groups (exposed and referent) and SEGs among brickfield workers.

Results Mean results were as follows for the SEGs, respectively for silica, RSPM and TSPM: red brick loading/carrying (RBL/C), $0.388 \mathrm{mg} / \mathrm{m}^{3}, 17.944 \mathrm{mg} / \mathrm{m}^{3}, 22.657 \mathrm{mg} / \mathrm{m}^{3}$; green brick stacking (GBS), $0.204 \mathrm{mg} / \mathrm{m}^{3}, 5.886 \mathrm{mg} / \mathrm{m}^{3}, 16.271 \mathrm{mg} /$ $\mathrm{m}^{3}$; green brick moulding (GBM), $0.119 \mathrm{mg} / \mathrm{m}^{3}, 2.193 \mathrm{mg} /$ $\mathrm{m}^{3}, 4.581 \mathrm{mg} / \mathrm{m}^{3}$; fire master (FM), $0.111 \mathrm{mg} / \mathrm{m}^{3}, 3.452 \mathrm{mg} /$ $\mathrm{m}^{3}, 3.435 \mathrm{mg} / \mathrm{m}^{3}$; and for coal crushing/carrying (CCC), $0.098 \mathrm{mg} / \mathrm{m}^{3}, 7.478 \mathrm{mg} / \mathrm{m}^{3}, 7.094 \mathrm{mg} / \mathrm{m}^{3}$. One-way ANOVA was conducted for silica, RSPM and TSPM showing significant relationships across the SEGs. The majority (55\%) of brick workers complained of coughing during the previous year. The prevalence of chronic cough among this group was $14.3 \%$ compared to $6.8 \%$ for grocery workers. Brick workers were also significantly more likely to have chronic phlegm production while coughing, chronic bronchitis, wheezing, chest tightness and other chest illnesses. Among SEGs, green brick moulders were nearly six times more likely to experience chronic cough (OR: 5.80; 95\% CI: 1.20 to 27.93; p: 0.028) with red brick loaders three times more likely to have chronic bronchitis (OR: 3.08; 95\% CI: 1.26 to 7.51; p: 0.013) when compared with workers involved in CCC work. Age and duration of work were significant predictors for chronic cough $(p=0.001$ each). Age of workers $(p=0.003)$ and smoking habit of workers $(p=0.002)$ were significant predictors for causing chronic bronchitis. Smoking practice of the workers was a significant predictor of wheezing $(\mathrm{p}=0.018)$ and asthma $(\mathrm{p}=0.026)$ among work groups.

Conclusions All of the respiratory symptoms and illnesses were significantly high among brickfield workers. These finding indicate urgent action for protection of workers and prevention of diseases. Furthermore, the symptoms and illnesses are the clear signs that exposure to TSPM, RSPM and silica are affecting the brickfield workers. 